\title{
Working Memory Training does not Improve Intelligence: Evidence from Brazilian Children
}

\section{Treinamento em Memória de Trabalho não Promove Mudanças Intelectuais: Evidências em Crianças Brasileiras}

\author{
Marcela Mansur-Alves* \& Carmen Flores-Mendoza \\ Universidade Federal de Minas Gerais, Belo Horizonte, MG, Brazil
}

\begin{abstract}
Recent investigations applying working memory training have indicated that it is possible to train intelligence. This work aimed to verify the effectiveness of a cognitive training program aimed at increasing children's intelligence. Fifty-three Brazilian children, enrolled in the sixth year of elementary school $(M=11.17$ years, $S D=.37)$, were selected from a larger original group. This selected sample was randomly assigned into the experimental group/EG $(n=27)$ and the control group/CG $(n=26)$. All children were evaluated by cognitive measures in the pre-test and post-test phase. Three working memory tasks encompassed the cognitive training program. The cognitive training was administered to the EG twice a week for eight weeks. The post-test assessment was administered two weeks following the conclusion of the training program. The statistical analysis indicated no significant differences between EG and CG after training for cognitive measurements. These results demonstrate partial support of the selective literature that indicates the difficulty of achieving significant intellectual changes through specific intervention programs.

Keywords: Training, intelligence, working memory, Brazilian children.
\end{abstract}

\begin{abstract}
Resumo
Investigações recentes utilizando a memória de trabalho tem mostrado que é possível treinar a inteligência. Este trabalho teve como objetivo verificar a efetividade de um programa de treinamento de memória de trabalho para melhorar a inteligência de crianças. Participaram do estudo cinquenta e três crianças brasileiras do sexto ano do ensino fundamental $(M=11,17$ anos, $D P=0,37)$, as quais foram aleatoriamente designadas para compor o grupo experimental/GE $(n=27)$ e o grupo controle/ GC $(n=26)$. No pré-teste e no pós-teste, as crianças foram avaliadas com medidas cognitivas e de desempenho escolar. Para o programa de treinamento foram utilizadas três tarefas de memória de trabalho. O treinamento cognitivo foi administrado ao GE duas vezes por semana por oito semanas. O pós-teste foi realizado duas semanas após o final do treinamento. Não foram encontradas diferenças significativas entre o grupo de treinamento e controle no pós-teste para nenhuma das medidas cognitivas e de desempenho escolar. Os resultados encontrados encontram suporte parcial na literatura e apontam para dificuldade de se encontrar mudanças intelectuais genuínas com programas de intervenção de curta duração.

Palavras-chave: Treinamento, inteligência, memória de trabalho, crianças brasileiras.
\end{abstract}

Intelligence can be understood as the capacity to solve problems, think abstractly, learn from experience and adapt to the environment (Gottfredson, 1997). Most researchers recognize the importance of intelligence for individual success in several aspects of life (Gottfredson, 2002; Strenze, 2007). In addition, this recognition may be further extended to countries, as well. For instance, the project entitled, Foresight Project on Mental Capital and Wellbeing, which involved 450 experts from 16 countries,

" Mailing address: Universidade Federal de Minas Gerais, Departamento de Psicologia, Faculdade de Filosofia e Ciências Humanas, Gabinete 4001, Avenida Presidente Antônio Carlos, 6627, Pampulha, Belo Horizonte, MG, Brazil 31270-901. E-mail: marcelamansuralves@yahoo.com.br it is emphasized that countries must be concerned with: (a) how to capitalize on their citizens's cognitive resources, (b) promoting early interventions, and (c) empowering people to develop and maintain their mental capital and wellbeing (Beddington et al., 2008). Thus, there is a renewed interest in the scientific literature regarding these interventions, whether at the individual or the national level, to increase the intelligence (or cognitive abilities) of people (Nisbett, 2009; Nisbett et al., 2012).

Among these interventions are those related to working memory (WM), understood as a cognitive system that stores and manipulates a limited amount of information for a short period of time (Baddeley, 2003). Several studies have showed a strong association between 
WM and superior cognitive functions, such as reading, reasoning and problem solving (Flores-Mendoza, Colom, Garcia, \& Castillo, 2001; Jaeggi, Buschkuehl, Jonides, \& Shah, 2011). In this sense, WM is considered a vehicle of change in intelligence, especially when considering 'fluid intelligence' (Gf), which refers to the capacity of reasoning and solving new problems, understanding meanings and adapting to uncommon situations (Jaeggi, Buschkuehl, Jonides, \& Perrig, 2008; Shipstead, Redick, \& Engle, 2010).

Several recent studies have indicated that adequate training can lead to an increase in WM test performance and can be transferred to the performance in non-trained cognitive tasks for children, adolescents, adults, and older subjects. Regarding studies conducted on children and adolescents, Klingberg et al. (2005) and Klingberg, Forssberg and Westerber (2002) reported that the training group outperformed the control group in the Raven test $(\mathrm{G} f$ measure). The efficiency of working memory training for children and teenagers (aged from 7 to 17 years) diagnosed with Attention Deficit Hyperactivity Disorder (ADHD) was also evaluated by Beck, Hanson, Puffenberger, Benninger, and Benninger (2010). Four months after the six week intervention, the experimental group outperformed the control group in all measurement of working memory categories (organization, metacognition, planning, proactivity). Alloway and Alloway (2009) promoted WM training to improve crystallized intelligence, which is the ability to use skills, knowledge, and experience. Fifteen children $(M=12.9$ years and $S D=.40$ years $)$ performed general knowledge measurements in the pre-test and post-test. When compared to the control group, the training group obtained high scores in general knowledge measurements after eight weeks of working memory training.

In another study, Jaeggi et al. (2011) aimed to verify the benefits of WM training in seventy-six children. The EG children $(M=9.12$ and $S D=1.52)$ were trained 5 days a week, during one month. The training task was a variant of the $n$-back visual-spatial task used by children with a videogame format. The Raven test and the Test of NonVerbal Intelligence (TONI), both measures of fluid intelligence, were used as pre-test and post-test measurements. The results indicated significant differences between EG and CG for both immediate post-test $(d=.55)$ and three months post-test $(d=.32)$ for both intelligence measurements. Carretti, Caldarola, Tencati, and Cornoldi (2014), Loosli, Buschkuehl, Perrig, and Jaeggi (2012) and Witt (2011) also reported an improvement in mathematical and reading performance following working memory training in a group of children aged 9 to 11 years.

Regarding adults and older subjects, Jaeggi et al. (2008) was one of the first to demonstrate the effectiveness of working memory training in the enhancement of $\mathrm{G} f$ of seventy healthy university students $(M=25.6$ years, $S D$ $=3.3$ years). The Raven test (Advanced Scale) and the Bochumer Matrices test (BOMAT) were used to evaluate
$\mathrm{G} f$ gains. The results showed that the EG increase was significantly higher than CG $(d=.65$ and $d=.25$, respectively). In another study using a sample of ninety-nine undergraduates (mean age $=19.4$ years; $S D=1.5 ; 76$ women), Jaeggi et al. (2010) showed transfer effects in matrix reasoning tasks after WM training, replicating theirs previous results. Shiran and Breznitz (2011) performed working memory training on a sample of 41 dyslexics (experimental group) and 50 normal readers (control group), samples taken from Israeli university students. After six weeks, the experimental group outperformed the control group when measuring working memory, verbal fluency and reading. Unfortunately, Shiran and Breznitz (2011) did not verify if the gains in working memory and reading led to changes in reasoning, as measured by intelligence tests. Similar results were reported in several studies involving young adults (Klingberg et al., 2002; Li et al., 2008; Rudebeck, Bor, Ormond, O'Reilly, \& Lee, 2012; Stephenson \& Halpern, 2013; von Bastian \& Oberauer, 2013), as well as in advanced age populations (Borella, Carretti, Riboldi, \& De Beni, 2010; Buschkuehl et al., 2008; Carretti, Borella, Zavagnin, \& De Beni, 2013; Li et al., 2008).

Interestingly, not every study revealed such convincing effects of training and transfer, while others described mixed results (Melby-Lervåg \& Hulme, 2013; Morrison \& Chein, 2011). For instance, a study with healthy preschoolers conducted by Thorell, Lindqvist, Bergman, Bohlin, and Klingberg (2009), using the same training procedure used by Klingberg et al. (2005), did not show an improvement in intelligence for the training group. Similarly, Holmes, Gathercole, and Dunnings (2009) were unable to replicate intelligence improvement in children using the same WM training program proposed by Klingberg et al. (2002). The effectiveness of computerized working memory (WM) training was investigated by Van der Molen, Van Luit, Van der Molen, Klugkist, and Jongmans (2010) in 95 adolescents with mild to borderline intellectual disabilities (IQ range $=55-85$ ) attending special education. No training effects on fluid intelligence and response inhibition were found. Prins, Dovis, Ponsioen, ten Brink, and van der Oord (2011) trained 51 children with ADHD, ages ranging from 7 to 12 years, which were randomly distributed to either WM in a videogame format or WM in a classical format. After three weeks of training, the results indicated an increase in working memory performance favoring the videogame training group $(p<.01)$, while no significant change was found in the classical training group, when comparing the pre-test to post-test, $(p=.29)$. Recently, Mansur-Alves, FloresMendoza and Tierra-Criollo (2013) conducted a small study on 16 Brazilian children $(M=8.75$ years, $S D=.44)$. The cognitive training was composed of computerized working memory tasks administered twice a week for two months. Despite an increase in all measurements, no significant differences in fluid intelligence or crystallized were observed between EG and CG. 
Chein and Morrison (2010) did not find an improved performance in neither the Raven test (Advanced scale) or on other reasoning tests for young adults, after four-week of WM training. The same result was obtained by Redick et al. (2013) who failed to observe any difference in the constructs or in the measured levels among their trained, active, and passive control young adults groups. Chooi and Thompson (2012) aimed to replicate and extend the findings previously reported by Jaeggi et al. (2008) in a psychology undergraduate sample. The results did not suggest an improvement in general intelligence following repeated training sessions applying a challenging working memory task. Also, Colom et al. (2013) aimed to analyse if adaptive working memory training would improve fluid intelligence, beyond the level of specific measures. For that purpose, 169 psychology undergraduates completed a battery of twelve intelligence tests and cognitive tasks. There were no significant differences between the trained and control groups for any construct assessed.

Studies conducted on older adults that employed working memory training (Buschkuehl et al., 2008) and strategic training (Carretti, Borella, \& De Beni, 2007) impacted memory performance, however no significant improvements on $\mathrm{G} f$ tasks were found. In conclusion, there are conflicting results in the literature regarding the real effect of cognitive training based on working memory verses intelligence performance.

Considering the lack of studies in developing countries designed to investigate the effects of WM training applied with the purpose of improving intelligence, this study aimed to present findings regarding the effectiveness of working memory training for children compared to intelligence performance.

\section{Method}

\section{Participants}

A Term of Informed Consent document was sent to the parents of all students who were attending the sixth grade in these three public schools located in the city of Belo Horizonte (Minas Gerais/Brazil). However, parents of only 53 students ( $58 \%$ of the sample), 31 girls and 22 boys, effectively authorized their participation in the study. The average age of the participant sample was of 11.17 years $(S D=.376), 26$ students randomly assigned to the control group and 27 students placed in the experimental group. No statistically significant difference was observed between the control and experimental groups, in regards to age or sex $(p>.05)$. With respect to IQ level, no statistically significant differences were observed between CG and EG, $t(52)=-.088 ; p=.930$, demonstrating that both groups had the same measured intelligence quotient. In addition, no differences in socioeconomic levels or parent educational were found. The study was approved by the Federal University of Minas Gerais Ethics Committee (Comitê de Ética em Pesquisa da Universidade Federal de Minas Gerais /0490.0.203.000-09).

\section{Instruments}

Cognitive Measurements. Two tests were used to measure intelligence in the pre-test and post-tests. The first was the Standard Progressive Matrices of Raven (SPM; Centro Editor de Psicologia Aplicada [CEPA], 2001). The SPM is the most commonly used non-verbal intelligence measurement in international research aimed at evaluating $\mathrm{G} f$ (fluid intelligence). In the current study, the Cronbach's alpha was .917, which indicated high internal consistency. The SPM was administered without time limit.

The second cognitive measurement was the Brazilian Cognitive Reasoning Battery (BPR5; Almeida \& Primi, 2000). BPR5 is a multidimensional cognitive battery which offers an estimate of reasoning ability in diverse cognitive areas. This battery is composed of five subtests (Verbal Reasoning [VR], Abstract Reasoning [AR], Mechanical Reasoning [MR], Spatial Reasoning [ER] and Numerical Reasoning [NR]). There are two BPR5 forms. The A form is for individuals with basic educational level, while the $\mathrm{B}$ form is appropriate for individuals with the minimum of a high school education. According to the manual, the instrument demonstrates good indexes of validity and reliability. Only the NR test was administered in the present study, which was limited to a time restriction of 18 minutes and was composed of 20 items. NR is associated with fluid and crystallised intelligence as it measures comprehension of basic quantitative concepts, such as addition, subtraction, multiplication and division and numerical symbol manipulation.

Training Program. A three task working memory program was developed for this study. These tasks were adapted from software developed by Flores-Mendoza et al. (2001) for WM evaluation in mentally deficient adults.

The Numerical Order task contains four difficulty levels (low, medium 1, medium 2, and high). The performance of several simple addition mathematical operations (e.g.: $1+1=$ ? and $4+3=$ ?) was required for this task. After completing the calculation, the values must be memorised and placed in ascending order. For each difficulty level, the values are more complex.

The Grammatical ABC task is composed by four difficulty levels (low, medium 1, medium 2 and high). The task consists of a series of sentences regarding letter position. The child must answer what is the correct order of the presented letters. The following is an example of a low difficulty level question: "A comes before B" (Screen 1); "What is the correct order? 1-BA or 2- AB" (option 2). An example of high difficulty question is as follows: "A comes before B" (Screen 1); "D comes after C" (Screen $2)$; "What is the correct order?: 1-ABCD; 2-BADC; 3-CDAB; 4-DCAB" (option 1). Each sentence is shown for 7 seconds (low level), 15 seconds (medium level) or 20 seconds (high level).

The Alphabet task is composed of three difficulty levels (low, medium and high) and it consists of a series of words whose first letter must be remembered and typed in alphabetical order (e.g.: MAU, BAR and CEU = B, C, M). 
Three-letter syllables words are shown for 2 seconds (low level), 5 seconds (medium level) or 8 seconds (high level).

For all three WM tasks, each difficulty level was composed of 30 trials and two training trials. For each answer, feedback was offered using a cartoon of "thumbs up" (correct) or "thumbs down" (incorrect). Also, the child moved automatically from one level to the next when he/ she reached $60 \%$ of the correct answers. This forward criterion was based on results from a previous study conducted by Mansur-Alves et al. (2013).

\section{Procedures}

Pre-Test Assessment. Between April and May 2011, sixth grade students from the three schools, whose participation was parent authorised, were evaluated using the SPM and NR. These tests were administered collectively in the classrooms during a 2 hour session. The pre-test was conducted two months before the first training session due to school break (June and July, in Brazil).

Cognitive Training. The cognitive training program started in August 2011 and concluded in October 2011. The experimental group was trained twice a week, for eight weeks. Each training session lasted a maximum of 50 minutes and it was conducted in school classrooms equipped with computers. Participants were trained in small groups of 2-3 students. All participating children from these three schools were previously familiarized with a computer. Before initiation of the training, instructions for each task, which were displayed on the computer screen, were read to each child by the research assistant. Two training trials were administered in order to verify if task was understood by the children. If necessary, the training trials were repeated. Initially, the performance of each WM task on level 1 was requested by each child. Since $60 \%$ of the correct answers were achieved, the next level was presented during the following session. If the passing criterion was not achieved, the lower level would be maintained. However, if the child remained on the same level for four consecutive sessions, the task was removed from the training. In order to keep the children motivated during the study, sweets (candy, snacks and chocolates) and tangible reinforcement (toys) were respectively offered after each session during the four weeks of training. The children from the control groups only attended the classes offered at the schools.

Post-Test Assessment. Post-test was administered two weeks after the last training session. The gap between training and post-test was similar across control and experimental groups. All children were submitted to the same items of Standard Progressive Matrices of Raven and BPR5-NR as the pre-test.

\section{Data Analysis}

Statistical analyses were performed with SPSS (Release 20.0). All statistical evaluations were based on a significance level of $\alpha=.05$. For the experimental group, the achieved number of correct answers was computed for each child, in each task and at each training level. Additionally, the average number of correct responses was computed for each task and training level.

For the transfer measures, we first tested whether the two groups differed in the pre-test using independent $t$ -tests. We analysed a global transfer effect in two ways. First, a multivariate analysis of variance (MANOVA) with group (experimental, control) as the between factor and the standardized change (using the formula: post-test - pre-test $/ S D$ pre-test) as dependent variables was used. Secondly, the Cohen's $d$ index estimate was used to better visualize, in standard deviation units (and, thus, IQ), the difference between groups before and after training. The $d$ index, or Cohen's difference, constitutes the differences between groups and is expressed in standard deviation units (Conboy, 2003). The formula for such a calculation is:

$$
\begin{aligned}
\text { (1) } d & =\frac{X 1-X 2}{S \text { pooled }}=\frac{X 1-X 2}{S \text { pooled }} \\
\text { (2) } s & =\sqrt{\frac{\left(n_{1}-1\right) s_{1}^{2}+\left(n_{2}-1\right) s_{2}^{2}}{n_{1}+n_{2}-2}} \\
s & =\sqrt{\frac{\left(n_{1}-1\right) s_{1}^{2}+\left(n_{2}-1\right) s_{2}^{2}}{n_{1}+n_{2}-2}}
\end{aligned}
$$

Where: (1) $X_{1}$ and $X_{2}$ are the averages of samples 1 and 2, respectively. Spooled is the grouped variance and is calculated using formula (2), $\mathrm{n}_{1}$ is the sample size of group $1 ; \mathrm{n}_{2}$ is the sample size of $2 ; \mathrm{S}_{1}$ is the standard deviation of group 1 and $\mathrm{S}_{2}$ is the standard deviation of group 2 .

\section{Results}

\section{Specific Training Effect}

Figure 1 demonstrates the results for the median (and standard deviation) of correct trials achieved by all children from the training group across each task level. The median was high for the first level of each training task, signifying that the expected improvement in the working memory tasks across sessions was not observed. Nevertheless, it's important to note that the variability in the achievement is larger for levels three and four, especially for the Alphabetic task, which posed the most difficulty.

\section{Transfer Effects}

Descriptive data for pre- and post-test scores for each group, as well as the effect sizes for the pre-post differences, are reported in Table 1. There were no significant differences between groups in any transfer measure from the pre-test. 


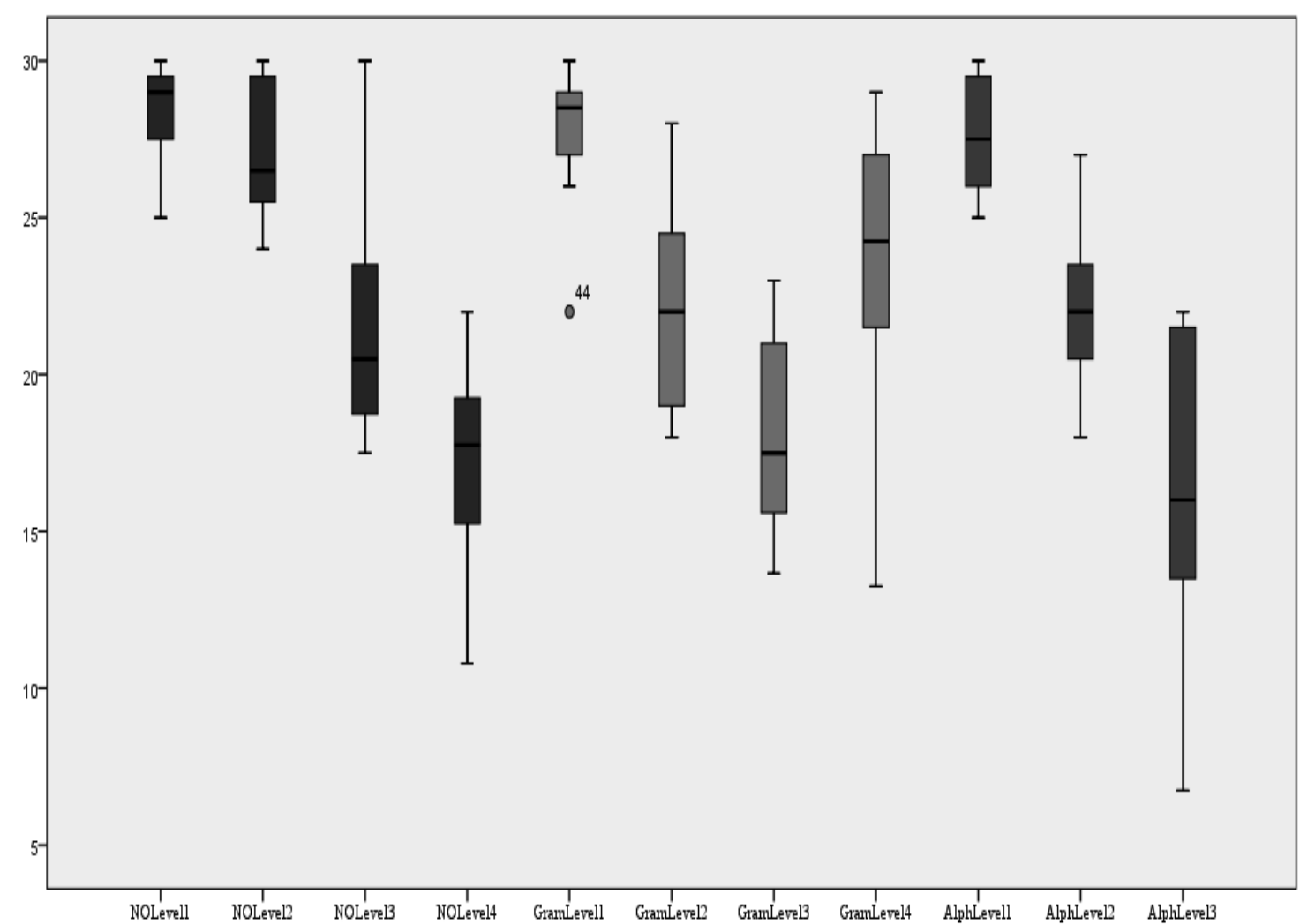

Figure 1. Median of correct trials achieved (Y-axis) by the training group $(n=27)$ across level of each task. NO= Numerical Order; Gram= Grammatical; Alph = Alphabet.

Table 1

Descriptive Data (mean and standard deviations) in Pre-and Post-Test Sessions for the Experimental and Control Group, as Well as Difference Scores and Effect Sizes (Cohen's d) for the Pre-and Post-Test Comparisons for Each Group

\begin{tabular}{cccc}
\hline Group & Pre-test & Post-test & $n$ \\
& & SPM & \\
Control & $40.27(9.44)$ & $39.23(9.02)$ & 26 \\
Experimental & $39.80(8.89)$ & $39.40(8.43)$ & $d=-.01$ \\
& $d=.05$ & Numerical Reasoning & 27 \\
Control & & $9.31(5.1)$ & 26 \\
Experimental & $8.92(5.4)$ & $7.47(3.72)$ & 27 \\
& $7.71(4.9)$ & $d=.42$ &
\end{tabular}

Note. Standard deviations are between parentheses; positive Cohen's $d$ index indicates a difference in favour of the control group, whereas the negative values indicate a difference in favour of the experimental group.

Figure 2 depicts the computed standardised changes for the results shown in Table 1. The MANOVA demonstrated that there was no significant effect of working memory training for cognitive tests. The results showed no difference in effects between groups, neither in SPM results, $F(1.53)=.979 ; p=.331 ; \eta 2=.034$, nor in Numerical Reasoning test, $F(1.53)=.240 ; p=.628$; $\eta 2=.009$.

Additionally, the pre-training $d$ index that was favourable to $\mathrm{CG}$ of .05 (or $.05 \times 15=.75$ IQ points) changed to favour EG at -.01 (or $.01 \times 15=.15$ IQ points) in the SPM test. For Numerical Reasoning, the favourable $d$ index 
of CG (.23 or 3.45 IQ points), before training, remained favourable in this group $(d=.42)$ following the training.
Therefore, in measures of intelligence, no clear pattern of gain was observed in either of the groups.

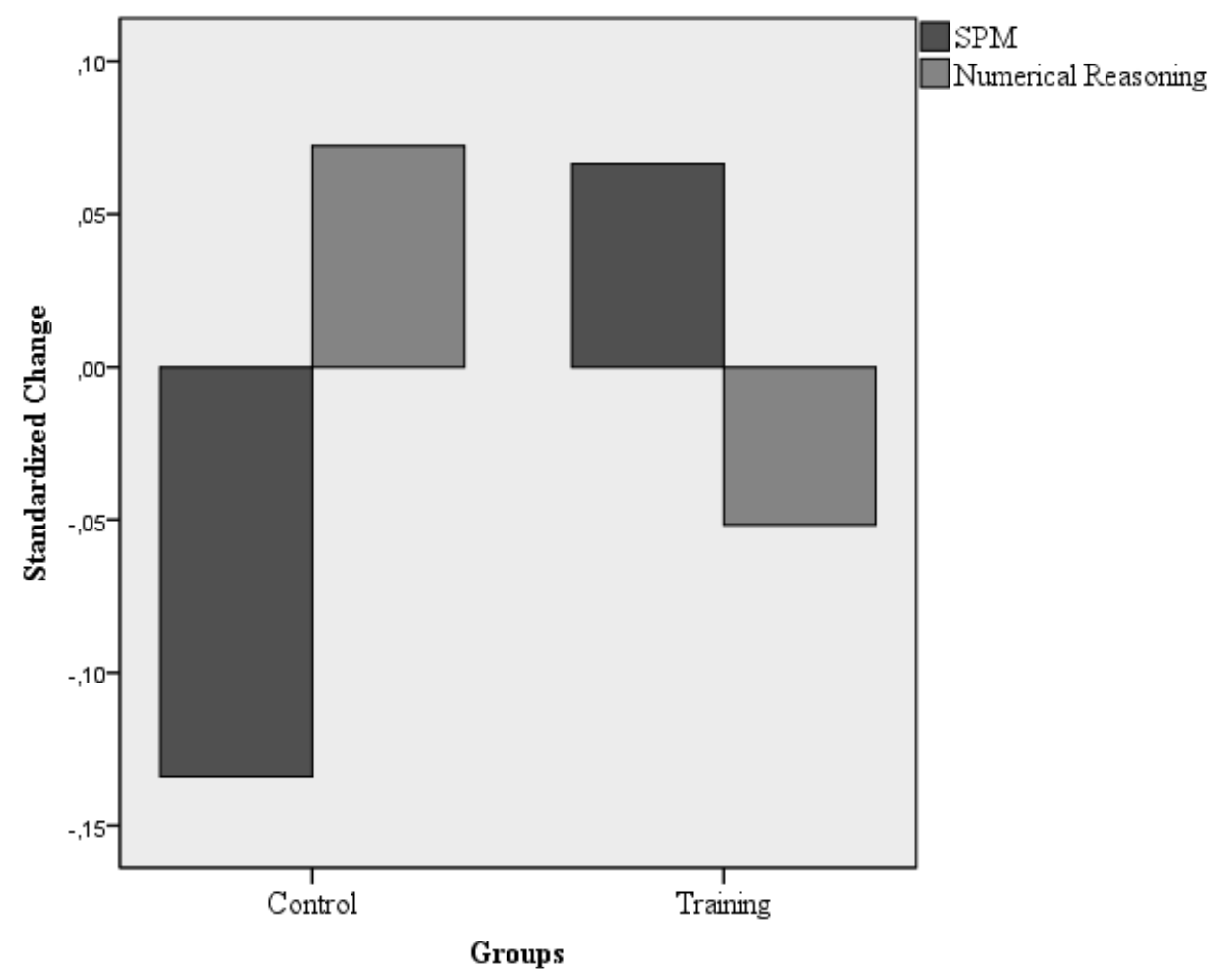

Figure 2. Standardized change (post-test - pre-test / SD at the pre-test) of the training and control groups in cognitive measures.

\section{Discussion}

Working memory has been seen as a possible and attractive alternative to solve the recurring problem of failed attempts to modify intelligence (Buschkuehl \& Jaeggi, 2010). Several studies have consistently indicated WM and intelligence, especially fluid intelligence, to psychologically isomorphic processes since both are stored in the same neural circuits, such as parietal and prefrontal cortices (Kane \& Engle, 2002).

In this sense, the present investigation aimed to verify the effectiveness of a working memory program to promote changes in intelligence in Brazilian children. The specific training data demonstrated that the children did not improved their performance in the trained tasks when comparing level 4 and level 1 performance for each WM task. The specific training curve differs from the majority of previous studies. Some studies reported a linear performance increase (Chein \& Morrison, 2010; Colom et al., 2013; Jaeggi et al., 2008; Klingberg et al., 2005; Loosli et al., 2012), while others have shown almost no training gain throughout the intervention (Buschkuehl et al., 2008, Thorell et al., 2009). According to Buschkuehl et al. (2008), it is possible to assume that these differences emerged due to the different task properties used in each study. For example, in our study, participants reported, that it was relatively easy to generate strategies to solve Level 1 and Level 2 problems ( 2 or 3 stimuli) from each WM Task. It might be possible that the participant's strategy was not enough to successfully solve the problems presented on levels 3 and 4 . Alternatively, it might also be possible that participants reached their capacity limit in WM Task Level 2, especially if we consider that some participants never attained the correct number of answers necessary to advance to the next level during the four consecutive training sessions. Therefore, further improvements may have been possible for these participants, however these two hypotheses need to be tested further in future studies.

Concerning the transfer measures, the intelligence averages in SPM and Numerical Reasoning did not significantly differ from the pre-test to the post-test in either groups (CG and $\mathrm{EG}$ ), although there was a tendency (but not significant) for a decrease in the variability for the experimental group following training. According to Borella et al. (2010), the positive gains from training are also supported by a decrease of variability (standard deviation), indicating an overall increase in test performance after the intervention.

Some studies, such as those of Alloway and Alloway (2009), Carretti et al. (2013), Jaeggi et al. (2008), Jaeggi 
et al. (2011), Klingberg et al. (2005), Klingberg et al. (2002) and Loosli et al. (2012), reported gains in WM training, specifically in relation to fluid and crystallised intelligence measurements. But other researchers, such as Chein and Morrison (2010), Holmes et al. (2009), Prins et al. (2011), Thorell et al. (2009) and Van der Molen et al. (2010), asserted that there was no evidence of transfer of WM training to fluid and crystallised intelligence.

According to Morrison and Chein (2011), these contradictory results can, in part, be explained by the different approaches adopted by the researchers in WM training. The advantage of this diversity is increasing the probability that some of them, or a combination of them, will produce the desired changes, though exactly which components that produced the cognitive change remains unknown. In other cases, there are unique training tasks, as demonstrated by the $n$-back tasks when applied by Jaeggi et al. (2008; Jaeggi et al., 2011). In these studies, the control over which task produced the observed changes is reported as the benefit.

Moreover, it is pertinent to note that our WM training has used only linguistic and numerical symbols, not visual-spatial components. Although it is not entirely true that transfer is only observed in the visuo-spatial domain for all kinds of trained tasks (Carretti et al., 2013; Loosli et al., 2012; von Bastian \& Oberauer, 2013) it is pertinent to speculate that the effectiveness of WM training registered in some studies could be narrowly connected to the inclusion of visual-spatial tasks, mostly when matrix reasoning tests are used as transfer tasks (Stephenson \& Halpern, 2013). For instance, cognitive instrument items, such as SPM and BOMAT and the WM tasks (employed in these studies), are of a visual-spatial nature (Abad, Colom, Rebollo, \& Escorial, 2004).

Interestingly, the ecologic validity of the tasks and motivational aspects deserve more attention. According to McDaniel and Bugg (2012), the trained strategies and the tasks used in laboratories have little similarity with the demands found by the subjects in their day-to-day lives. Training tasks with direct repercussion to life would yield more positive results in the measured levels of nervous system plasticity (Maguire et al., 2000; Maguire et al., 2003).

Regarding motivational aspects, McDaniel and Bugg (2012) asserted that if a wide variety of stimuli was inserted, children and elders can maintain attention and engagement for a longer period of time. Unfortunately, no objective measurement of motivation was used to evaluate the children's involvement in the present study.

Another issue discussed is the time and schedule of the training sessions (McDaniel \& Bugg, 2012). Studies in this field include training programs which have a minimum duration of two weeks and a maximum of 15. On the one hand, some authors (Neisser et al., 1996; Nisbett et al., 2012) think it is naïve to suppose that the practice of certain tasks, concentrated in a short period of time, would reflect on genuine intellectual changes (real gains in general intelligence) if the intelligence is one of the most stable psychological constructs along the vital cycle and is highly heritable. On the other hand, other authors identified that the practice distribution during the sessions could be more important than the duration of training, per se. Cepeda, Pashler, Vul, and Wixted (2006) speculate that it is important to leave sufficient time to consolidate the skills the participants acquired with a fixed interval between sessions, and at the same time, remain sufficiently condensed in order to minimize the risk that the participants will lose the beneficial effects of having practiced the task.

Morrison and Chein (2011) propose alternative interpretations for the few intellectual gains found in reports. According to these authors, small gains could be the result of the level of investment of the participants and the expectations they have with the study. This is more evident in studies that include control groups with no contact with the researchers. In these cases, it is believed that the control subjects do not experience the same motivation or have similar expectations as the experimental group concerning training benefits and straining less in the post-test evaluations to show positive results. However, the Morrison and Chein's observation were not supported by the present study. The control group was not inferior to that of the experimental group in the post-test evaluations.

To summarize, the results found in the present study and the issues discussed above, challenge the possibility of modifying intelligence based on the existing WM training programs. Incongruous results have led some authors to request care in the interpretation of positive study results (Melby-Lervåg \& Hulme, 2013), while others are still optimistic with the successful outcomes (Klingberg, 2010). One of the greatest obstacles in forming solid conclusions regarding the WM training program effectiveness could be the lack of methodological consistency between the studies (Melby-Lervåg \& Hulme, 2013; Morrison \& Chein, 2011). The main inconsistencies include: training period, training session duration, number of evaluation sessions and the instruments used, training location (at home, at the laboratory or and at school), type of WM task used and the type of control group used. Furthermore, despite the existence of solid evidences that environmental factors can stimulate the cognitive development (e.g. Flynn Effect) and allowing neural plasticity (Maguire et al., 2000; Nisbett, 2009; Nisbett et al., 2012; Turkheimer, Haley, Waldron, \& D'Onofrio, 2003) the failure of some studies ability to raise intelligence have served to rekindle the old belief that intelligence cannot be modified (Jensen, 1981).

Finally, we are aware that our study presents some methodological limitations. The sample size is far from ideal for generalization proposes and we used only a limited number of transfer measures. In future studies, other cognitive processes, such as short-term memory, attention, writing and reading skills could be trained. In addition, we had difficulties to control some possible bias in the training procedure, like participant's motivation and no stable training schedule due to the school calendar. 
These conditions would have had a negative effect on participant's performance. Last but not least, our study is the first working memory intervention to improving intelligence conducted in a developing country, and our results did not differed from the claim of traditional differential psychology: short interventions still do not seem to be effective to modify intelligence, a very stable and solid psychological construct.

\section{References}

Abad, F. J., Colom, R., Rebollo, I., \& Escorial, S. (2004). Sex differential item functioning in the Raven's Advanced Progressive Matrices: Evidence for bias. Personality and Individual Differences, 36, 1459-1470. doi:10.1016/S01918869(03)00241-1

Alloway, T. P., \& Alloway, R. G. (2009). The efficacy of working memory training in improving crystallized intelligence. $\mathrm{Na}$ ture Precedings. Retrieved from http://hdl.handle.net/10101/ npre.2009.3697.1

Almeida, L., \& Primi, R. (2000). Bateria de Provas de Raciocínio - BPR-5: Manual de aplicação. São Paulo, SP: Casa do Psicólogo.

Baddeley, A. (2003). Working memory: Looking back and looking forward. Nature Reviews: Neuroscience, 4, 829-839. doi:10.1038/nrn1201

Beck, S. J., Hanson, C. A., Puffenberger, S. S., Benninger, K. L., \& Benninger, W. B. (2010). A controlled trial of working memory training for children and adolescents with ADHD. Journal of Clinical Child \& Adolescent Psychology, 39, 825836. doi:10.1080/15374416.2010.517162

Beddington, J., Cooper, L., Field, J., Goswami, U., Huppert, F., Jenkins, R., ...Thomas, S. (2008). The mental wealth of nations. Nature, 455, 1057-1060. doi:10.1038/4551057a

Borella, E., Carretti, B., Riboldi, F., \& De Beni, R. (2010). Working memory training in older adults: Evidence of transfer and maintenance effects. Psychology and Aging, 25, 767-778. doi:10.1037/a0020683

Buschkuehl, M., \& Jaeggi, S. M. (2010). Improving intelligence: A literature review. Swiss Medical Weekly, 140, 266-272.

Buschkuehl, M., Jaeggi, S. M., Hutchison, S., Perrig-Chiello, P., Dapp, C., Muller, M., \& Perrig, W. J. (2008). Impact of working memory training on memory performance in old-old adults. Psychology and Aging, 23, 743-753. doi:10.1037/ a0014342

Carretti, B., Borella, E., \& De Beni, R. (2007). Does strategic memory training improve the working memory performance of younger and older adults? Experimental Psychology, 54, 311-320. doi:10.1027/1618-3169.54.4.311

Carretti, B., Borella, E., Zavagnin, M., \& De Beni, R. (2013). Gains in language comprehension relating to working memory training in healthy older adults. International Journal of Geriatric Psychiatry, 28, 539-546. doi:10.1002/gps.3859

Carretti, B., Caldarola, N., Tencati, C., \& Cornoldi, C. (2014). Improving reading comprehension in reading and listening settings: The effect of two training programmes focusing on metacognition and working memory. British Journal of Educational Psychology, 84, 194-210. doi:10.1111/bjep.12022

Centro Editor de Psicologia Aplicada. (2001). Manual das Matrizes Progressivas de Raven - Escala Geral. Séries A, $B, C, D$ e E. (2. ed., F. Campos, Trad. \& Adaptação). Rio de Janeiro, RJ: Autor.
Cepeda, N. J., Pashler, H., Vul, E., \& Wixted, J. T. (2006). Distributed practice in verbal recall tasks: A review and quantitative synthesis. Psychological Bulletin, 132, 354-380. doi:10.1037/0033-2909.132.3.354

Chein, J. M., \& Morrison, A. B. (2010). Expanding the mind's workspace: Training and transfer effects with a complex working memory span task. Psychonomic Bulletin, \& Review, 17, 193-199. doi:10.3758/PBR.17.2.193

Chooi, W., \& Thompson, L. A. (2012). Working memory training does not improve intelligence in healthy young adults. Intelligence, 40, 531-542. doi:10.1016/j.intell.2012.07.004

Colom, R., Romána, F. J., Abad, F. J., Shiha, P. C., Privado, J., Froufea, M., ...Jaeggi, S. M. (2013). Adaptive n-back training does not improve fluid intelligence at the construct level: Gains on individual tests suggest that training may enhance visuospatial processing. Intelligence, 41, 712-727. doi:10.1016/j.intell.2013.09.002

Conboy, J. E. (2003). Algumas medidas típicas univariadas da magnitude do efeito. Análise Psicológica, 21, 145-159.

Flores-Mendoza, C. E., Colom, R. B., Garcia, L. F., \& Castilho, A. V. (2001). Dificultades en el rendimiento escolar y la memoria de trabajo. Boletim de Psicología, 1, 21-36.

Gottfredson, L. S. (1997). Mainstream science on intelligence: An editorial with 52 signatories, history, and bibliography. Intelligence, 24, 13-23. doi:10.1016/S0160-2896(97)90011-8

Gottfredson, L. S. (2002). Where and why $g$ matters: Not a mystery. Human Performance, 15, 25-46. doi:10.1080/089 59285.2002.9668082

Holmes, J., Gathercole, S. E., \& Dunning, D. L. (2009). Adaptive training leads to sustained enhancement of poor working memory in children. Developmental Science, 12, 9-15. doi:10.1111/j.1467-7687.2009.00848.x

Jaeggi, S. M., Buschkuehl, M., Jonides, J., \& Perrig, W. J. (2008). Improving fluid intelligence with training on working memory. Proceedings of the National Academy of Sciences, 105, 6829-6833. doi:10.1073/pnas.0801268105

Jaeggi, S. M., Buschkuehl, M., Jonides, J., \& Shah, P. (2011). Short- and long-term benefits of cognitive training. Proceedings of the National Academy of Sciences, 108, 1008110086. doi:10.1073/pnas. 1103228108

Jaeggi, S. M., Studer-Luethi, B., Buschkuehl, M., Suc, Y. F., Jonides, J., \& Perrig, W. J. (2010). The relationship between n-back performance and matrix reasoning: Implications for training and transfer. Intelligence, 38, 625-635. doi:10.1016/j. intell.2010.09.001

Jensen, A. R. (1981). Raising the IQ: The Ramey and Haskins Study. Intelligence, 5, 29-40. doi:10.1016/01602896(81)90015-5

Kane, M. J., \& Engle, R. W. (2002). The role of prefrontal cortex in working-memory capacity, executive attention, and general fluid intelligence: An individual differences perspective. Psychonomic Bulletin and Review, 9, 637-671. doi:10.3758/ BF03196323

Klingberg, T. (2010). Training and plasticity of working memory. Trends in Cognitive Sciences, 14, 317-324. doi:10.1016/j. tics.2010.05.002

Klingberg T., Fernell, E., Olesen, P. J., Johnson, M., Gustafsson, P., Dahlstrom, K., ...Westerberg, H. (2005). Computerized training of working memory in children with ADHD - A randomized, controlled trial. Journal of American Academic Child Adolescent Psychiatry, 44, 177-186. doi:10.1097/00004583-200502000-00010 
Klingberg, T., Forssberg, H., \& Westerberg, H. (2002). Training of working memory in children with ADHD. Journal of Clinical Experimental Neuropsychology, 24, 781-791. doi:10.1076/ jcen.24.6.781.8395

Li, S. C., Schmiedek, F., Huxhold, O., Röcke, C., Smith, J., \& Lindenberger, U. (2008). Working memory plasticity in old age: Practice gain, transfer, and maintenance. Psychology and Aging, 23, 731-742. doi:10.1037/a0014343

Loosli, S. V., Buschkuehl, M., Perrig, W. J., \& Jaeggi, S. M. (2012). Working memory training improves reading processes in typically developing children. Child Neuropsychology, 18 , 62-78. doi:10.1080/09297049.2011.575772

Maguire, E. A., Gadian, D. G., Johnsrude, I. S., Good, C. D., Ashburner, J., Frackowiak, R. S. J., \& Frith, C. D. (2000). Navigation-related structural change in the hippocampi of taxi drivers. Proceedings of the National Academy of Sciences USA, 97, 4398-4403. doi:10.1073/pnas.070039597

Maguire, E. A., Spiers, H. J., Good, C. D., Hartley, T., Frackowiak, R. S. J., \& Burgess, N. (2003). Navigation expertise and the human hippocampus: A structural brain imaging analysis. Hippocampus, 13, 208-217. doi:10.1002/hipo.10087

Melby-Lervåg, M., \& Hulme, C. (2013). Is working memory training effective? A meta-analytic review. Developmental Psychology, 49, 270-291. doi:10.1037/a0028228

Mansur-Alves, M., Flores-Mendoza, C., \& Tierra-Criollo, C. J. (2013). Evidências preliminares da efetividade do treinamento cognitivo para melhorar a inteligência de crianças escolares. Psicologia: Reflexão e Crítica, 26, 423-434. doi:10.1590/ S0102-79722013000300001

McDaniel, M. A., \& Bugg, J. M. (2012). Memory training interventions: What has been forgotten? Journal of Applied Research in Memory and Cognition, 1, 45-50. doi:10.1016/j. jarmac.2011.11.002

Morrison, A. B., \& Chein, J. M. (2011). Does working memory training work? The promise and challenges of enhancing cognition by training working memory. Psychonomic Bulletin Reviews, 18, 46-60. doi:10.3758/s13423-010-0034-0

Neisser, U., Boodoo, G., Bouchard, T. J., Jr., Boykin, A. W., Brody, N., Ceci, S. J., ...Urbina, S. (1996). Intelligence: Knowns and unknowns. American Psychologist, 51(2), 77.

Nisbett, R. E. (2009). Intelligence and how to get it: Why schools and cultures count. New York: W. W. Norton.

Nisbett, R. E., Aronson, J., Blair, C., Dickens, W., Flynn, J., Halpern, D., \& Turkheimer, E. (2012). Intelligence: New findings and theoretical developments. American Psychologist, 67, 130-159. doi:10.1037/a0026699

Prins, P. J. M., Dovis, S., Ponsioen, A., ten Brink, E., \& van der Oord, S. (2011). Does computerized working memory training with game elements enhance motivation and training efficacy in children with ADHD? Cyberpsychology, Behavior, and Social Networking, 14, 115-122. doi:10.1089/cyber.2009.0206

Redick, T. S., Shipstead, Z., Harrison, T. L., Hicks, K. L., Fried, D. E., Hambrick, D. Z., ...Engle, R. W. (2013). No evidence of intelligence improvement after working memory training: A randomized, placebo-controlled study. Journal of Experimental Psychology: General, 142, 359-379. doi:10.1037/ a0029082

Rudebeck, S. R., Bor, D., Ormond, A., O’Reilly, J. X., \& Lee, A. C. H. (2012). A potential spatial working memory training task to improve both episodic memory and fluid intelligence. PLoS ONE, 7, e50431. doi:10.1371/journal.pone.0050431

Shipstead, Z., Redick, T. S., \& Engle, R. W. (2010). Does working memory training generalize? Psychologica Belgica, 50, 245-276. doi:10.5334/pb-50-3-4-245
Shiran, A., \& Breznitz, Z. (2011). The effect of cognitive training on recall range and speed of information processing in the working memory of dyslexic and skilled readers. Journal of Neurolinguistics, 24, 524-537. doi:10.5334/pb-50-3-4-245

Stephenson, C. L., \& Halpern, D. F. (2013). Improved matrix reasoning is limited to training on tasks with a visuospatial component. Intelligence, 41, 341-357. doi:10.1016/j.intell.2013.05.006

Strenze, T. (2007). Intelligence and socioeconomic success: A meta-analytic review of longitudinal research. Intelligence, 35, 401-426. doi:10.1016/j.intell.2006.09.004

Thorell, L. B., Lindqvist, S., Bergman, N. S., Bohlin, G., \& Klingberg, T. (2009). Training and transfer effects of executive functions in preschool children. Developmental Science, 12, 106-113. doi:10.1111/j.1467-7687.2008.00745.x

Turkheimer, E., Haley, A., Waldron, M., \& D'Onofrio, B. (2003). Socioeconomic status modifies heritability of IQ in young children. Psychological Science, 14, 623-628. doi:10.1046/j.0956-7976.2003.psci_1475.x

Van der Molen, M. J., Van Luit, J. E., Van der Molen, M. W., Klugkist, I., \& Jongmans, M. J. (2010). Effectiveness of a computerised working memory training in adolescents with mild to borderline intellectual disabilities. Journal of Intellectual Disability Research, 54, 433-447. doi:10.1111/j.13652788.2010.01285.x

Von Bastian, C., \& Oberauer, K. (2013). Distinct transfer effects of training different facets of working memory capacity. Journal of Memory and Language, 69, 36-58. doi:10.1016/j. jml.2013.02.002

Witt, M. (2011). School based working memory training: Preliminary finding of improvement in children's mathematical performance. Advances in Cognitive Psychology, 7, 7. 